\title{
The Consciousness-Intelligence-Knowledge Pyramid: An 8x8 Layer Model
}

\author{
https://doi.org/10.3991/ijes.v5i3.7680 \\ Athanasios S. Drigas ${ }^{\square}$, Marios A. Pappas \\ National Center for Scientific Research "Demokritos”, Agia Paraskevi, Attica, Greece \\ dr@it.demokritos.gr
}

\begin{abstract}
Cognitive and metacognitive skills are recognized and studied since antiquity. From the theory of Aristotle, according to which knowledge is product of the human mind and Platonic gnosiology and the theory of true knowledge, to the modern cognitive science, the question of how people acquire knowledge, has occupied a multitude of scientists. In this article we present a cognitive-based approach to the process of acquiring knowledge, we analyze the dominant theories of knowledge, theories of intelligence, as well as learning theories, and thus we propose an eight-layer pyramid of knowledge. We also analyze the cognitive processes and metacognitive skills required to get an individual to the highest layer of the knowledge pyramid.
\end{abstract}

Keywords—knowledge pyramid; cognitive skills; metacognition; intelligence; consciousness

\section{Introduction}

Two people read the same book but they draw different meanings. Two friends watch the same movie: one is inspired by the movie as it transmits to him senses that resemble his own experiencees, while the other finds no interest. Two classmates attend the same lecture but keep different notes and retain different data. Even the same person in similar situations, during different phases of his life, may realize things otherwise and collect different amounts of information through the stimuli provided. Universe is a 'hard disk' full of stimuli. Human brain, transforms these stimuli into data, and data into information, through the cognitive functions. Through the information we receive, we start the hunt of acquiring more and more knowledge. Some of this information we are not ready to perceive, while most of it we will never perceive. Intelligence, as well as cognitive functions, play a decisive role in whether we are ready to perceive the existing information around us and gain knowledge. People should continiously train and improve their cognitive skills through knowledge, in order to perceive more and more information and thus knowlegde, from the innumerable stimuli that exist in the universe.

In this paper we are going to analyze the most discussed theories of intelligence, as well as the knowledge theories. We propose a cognitive-based approach of an 8-layer model (pyramid) of knowledge, which adapts to the different types of human 
intelligence, and we define the metacognitive components that will help us move from one layer to the other and finally reach the top of the knowledge pyramid.

\section{Theories of Knowledge \& Learning.}

According to Piaget's interpretation, the process of learning and the acquisition of knowledge are based on the evolution of intelligence. In other words, the process of gaining knowledge (in a wider sense) and the evolution of intelligence could be considered as the same thing. In his effort to analyze the psycho-spiritual development of children and adolescents, Piaget (1936) presented the Developmental Stage Theory. Piaget's theory of cognitive development consists of four stages, each one of them builds on the previous: Sensorimotor Stage (0-2 years) where children learn how to coordinate sensory data and motor skills in order to understand their environment, Preoperational Stage (2-6 years) where children present symbolic thinking without cognitive processes, Concrete Operational Stage (7-12 years) during which there are signs of verbal understanding and logical reasoning, and Formal Operational Stage (12 years and above) where adolescents present abstract reasoning [1]. Benjamin Bloom (1956) created a taxonomy with six levels of reasoning skills (Knowledge, Comprehension, Application, Analysis, Synthesis and Evaluation). Teachers should guide students, so that they move up the taxonomy of learning objectives, as they progress in their abstract reasoning [2]. Anderson \& Krathwohl (2001) proposed the Revised Bloom's Taxonomy, an update of the original one dimensional Taxonomy to two dimensions, the Knowledge Dimension (factual, conceptual, procedural, metacognitive) and the Cognitive Process Dimension (remember, understand, apply, analyse, evaluate, create) [3]. The structural changes on Bloom's Taxonomy, enabled the utilization of the two dimensional framework (Taxonomy table) in the curriculum and instruction, based on stated objectives, instructional activities and assessments [4]. In 1982, Biggs \& Collis presented the SOLO Taxonomy (Structure of the Observed Learning Outcome) an instructional / evaluative tool which could be used by educators, in prder to evaluate learning quality in various subject areas. The SOLO Taxonomy describes five different levels of understanding: 1. Pre-Structural Level, 2. Uni-Structural Level, 3. Multi-Structural Level, 4. Relational Level and 5. Extended Abstract Level. Teacher can adapt the idea of the Taxonomy to his /her specific classroom needs and differentiate the instruction as well as the evaluation, to optimise learning outcomes [5]. Gagné (1970) approached knowledge selectively and tried to classify the theories of knowledge hierarchically. His taxonomy is actually a classification of learning consisting of five types: Intellectual Skills, Cognitive Strategy, Verbal Information, Attitude and Motor Skills [6]. According to Gagné each of these five learning outcomes requires a different kind of instruction [7]. Ackoff (1989) in his article From Data to Wisdom proposed a model (wisdom hierarchy) including the following levels:

$$
\text { Data } \rightarrow \text { Information } \rightarrow \text { Knowledge } \rightarrow \text { Understanding } \rightarrow \text { Wisdom }
$$


His model could be considered as pyramid as each level includes the previous levels. According to Ackoff, wisdom is the ability to increase effectiveness, while intelligence is the ability to increase efficiency [8]. Bellinger, Castro \& Mills (2004) considered understanding, more as a cognitive process that supports transition from one level to another, than a separate level, transforming thus Ackoff's model to the Data-Information-Knowledge-Wisdom (DIKW) hierarchy [9].

\section{The Pyramid of Knowledge}

Individuals have to improve their skills of observing control, as well as of adapting their cognitive processes, through mental self-observation of their cognitive skills, in order to complete successfully the process of 'building' the pyramid of knowledge (Figure 1) and utilize the information to reach the top layer. As we can perceive, for each layer of the pyramid of knowledge we have to define these skills that will help individuals to organize their knowledge, in order to jump directly to the next layer (Figure 2). In other words, it is obvious that metacognitive skills of each layer are not necessary the same with any other layer.Preschool children observe stimuli and behaviour and using their awareness of conflicting mental representaions give meaning to various concepts [10]. Invading stimuli enter encoded, as neural representations, into the cognitive processing system and thus can be used for subsequent processing [11].

Data is a collection of facts, generated by sensory stimuli that individuals perceive through their senses [12]. According to the definition of Information Science, the term data refers to the unprocessed information that have no inherent structure and are not always correlated to each other [13]. Data, if processed, acquire meaning and compile information. Correlation and synthesis of data should be governed by specific rules. Through these rules, individuals give value to a given set of data and store in their memory the resulting information or store the data as such for a possible later exploitation.

The information generated by the human brain every day, is of particular importance, as it is the basis for gaining knowledge through their systematic organization. Information could be defined as organized and structured data. The importance of some data for a specific purpose differs among individuals, as it depends on their cognitive schema and the existence of other relative information [14]. There is a clear distinction between the terms information and knowledge. The amount of information we perceive will not necessarily lead to the process of knowing. This explains a certain pathogenicity of the educational system, as in many cases students acquire information but not knowledge [15].

Human brain transforms information into knowledge through personal experience, beliefs and values, and thus knowledge formed though the same information differs from an individual to another [16]. Individuals engage with information processing in order to discover relations between concepts and construct knowledge [17]. We could discern knowledge in general, defined as understanding of general concepts and 
theories, and contextual, refering to individuals who can answer basic questions about a particular subject, drawing on general knowledge [18].

Expertise could be characterized as well-organised and interconnected domain specific knowledge, which allows individuals (experts) to overlap working memory limitations [19]. Expertise offers to the individual a wide range of cognitive capabilities, including the ability to make reliable and consistent discriminations between different stimuli, to estimate numerical values, to predict future outcomes, etc. [20]. If we look back at Plato's theory of knowledge we will see that through 'aitias logismos' as presented in Meno, Plato makes a crusial discrimination for gnosiology in general between 'true belief' and 'knowledge', as true beliefs are not fully immovable in the way we consider the knowledge is [21]. In order to be reliable, cognitive mechanisms of individuals should enable them to discriminate incompatible status of affairs [22].

According to Rogers (1959), from the bith of an individual and through his life, the only driving force is the tendency for actualization, while aiming at the positive recognition from his/her social environment [23]. The process of becoming an expert requires the development of creativity, motivation and self-actualization, and in most cases involves failure [24]. According to Mashlow (1965), the far objective of selfactualization is the intrinsic learning, i.e. to help people achieve what they are capable of. Individuals can reach self-actualization, only if they have covered all of their other needs and are now possessed by the desire for creativity [25]. Based on an optimistic view of the human nature, Carl Rogers argues that the only driving force of every individual is the tendency of self-actualization [26]. The achievement of selfactualization makes more possible self-transcedence, as the individual can merge himself/herself as a part of a larger whole [27].

With the term universal knowledge, we define the integrated knowledge that unites all the existing theories of the universe, in one global theory. Hawking (1979) presented an innovative theory of cosmology, based on the union of Einstein's general relativity and quantum mechanics [28]. Following the example of physicists, in his 'Theory of Everything', Wilber (2001) attempted to relate the unrelatable, as he suggested a model which combines human psychological and behavioral development, with cultural and social development. Unification of laws and theories governing the universe, requires expertise in various knowledge domains, mastering of self-skills and the abitity to see what others don't [29].

According to Mashlow (1969), the sense of getting absorbed, fascinated and concentrated, could lead an individual out of his/her own psyche and cause loss of self-consiousness and finally transcedence of the ego [30]. Transcendence is strongly correlated with self-esteem and emotional well-being. Individuals who have reached self-transcendence can encourage others to expand self-boundaries and self-actualise [31]. There is a clear coreelation between Sternberg's theory of wisdom, talking about the balance between intrapersonal, interpersonal and extrapersonal interests in order to achieve a common good, and Mashlow's notion of self-transcendence [32]. The notion of self-transcendence is similar to Habernas' emancipator form of knowledge, which involves increasing freedom from biological and social conditioning [33]. 


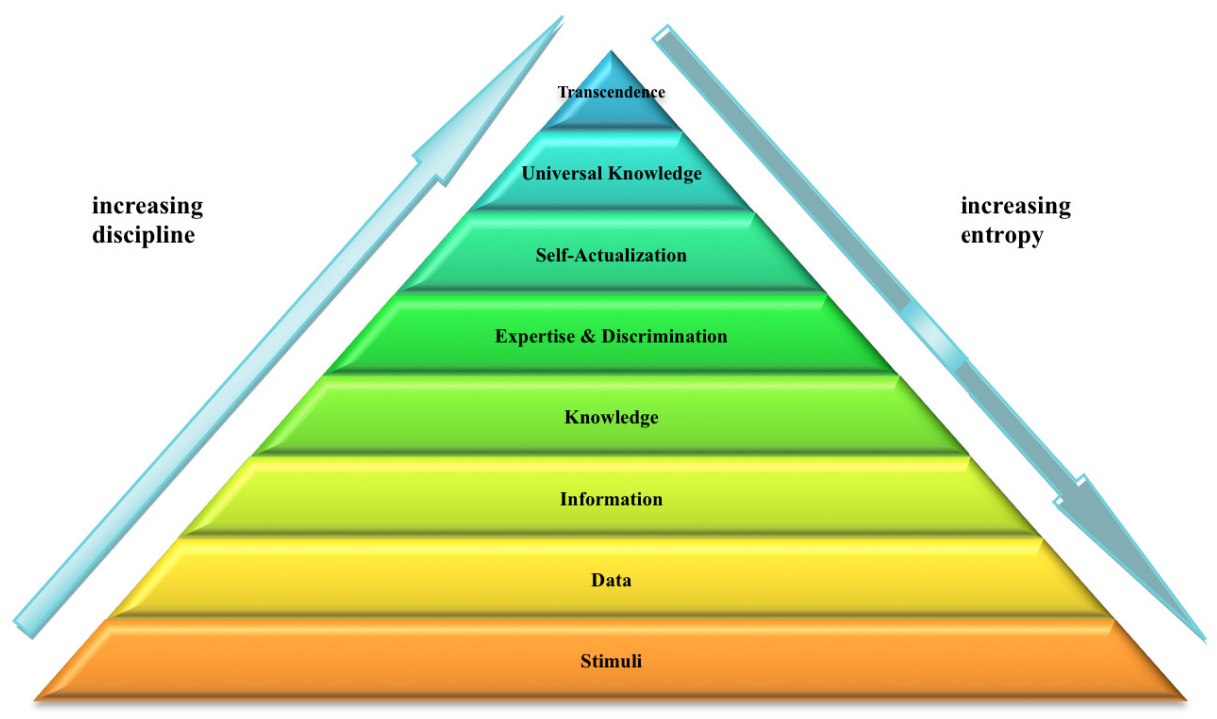

Fig. 1. The Knowledge Pyramid ( 8 Layer Model). Stimuli (neural representations), Data (recruitment of discrete elements, communication), Information (interconnected data), Knowledge (Acceptance, interest in knowledge, organization of information, theories, axioms), Expertise \& Discrimination (applied knowledge, creativity, experience, skills), Self-Actualization (Desire for creativity / innovation, mastering of skills), Universal Knowledge (Unification of laws and theories, conceptualization, prediction of behavior, needs and problems, problem solving) Transcendence (Self-forgetfulness, loss of self-consciousness, transcendence of ego).

\section{Metacognitive Procedures-Consciousness}

The cognitive processes of the human brain contribute to the organization and representation of knowledge. These cognitive structures and processes change as the individual evolves, acquires experiences and conquers knowledge. Cognition consists of a set of skills and brain functions through which individuals perceive their environment. Cognitive skills, such as working memory, attention, perception, visuospatial processing and various executive skills, play a crusial role in the formation of the learning process. Development of cognition requires a rich knowledge base. Cognitive skills should be considered as general tools for retrieving and managing domain-specific knowledge [34]. Adolescence is a crusial period for cognitive development though the formation of a conscious, self-directed and self regulating mind [35]. Cognitive enrichment depends on the magnitude to which individuals have occupied procedural skills, as well as on their prior knowledge and expertise, and requires promotion of meaningful intellectual activities [36].

Development of meta-cognitive procedures, which we define as monitoring, regulation and adaptation, or in one word consciousness, is the key for the individuals in order to move from one layer to the next one. We consider consciousness as the axis that supports the pyramid of knowledge, as it is a private, continuous and always- 
changing process, and not a state [37]. Metacognition is the ability of individuals to know their cognitive functions, monitor them while they operate, to control and adjust them, in order to optimize the adjustment to equivalent needs and requirements presented during the whole learning process [38, 39]. Researchers indicate a variety of components and subcomponents of metacognition, such as metamemory, monitoring, feeling of knowledge, judjment of learning and conditional knowledge [40]. Development of metacognition and specifically of monitoring, regulation and adaptation, requires training of cognitive skills, such as attention, short-term and working memory.

Information seems to have a negative correlation with the probability of an event occuring. The less likely is an event to occur, the greater the amount of information it delivers. In an attempt to quantify the information, researchers called this amount, entropy [41, 42]. According to the seceond law of thermodynamics, all spotaneous changes lead to an increase of the entropy in the universe. In the case of knowledge, if entropy of the environment increases more than the entropy of the system decreases, the overall change will be positive. Consequently, in order to move a system to higher energy levels and greater organization, there must be energy expense. In the pyramid of knowledge, in order to move from a layer to the higher one, some kind of energy should intervene and so we can go from senses to data, from data to information, from information to knowledge and so on. According to the constructivist perspective, gaining knowledge could be performed through self-organization [43].

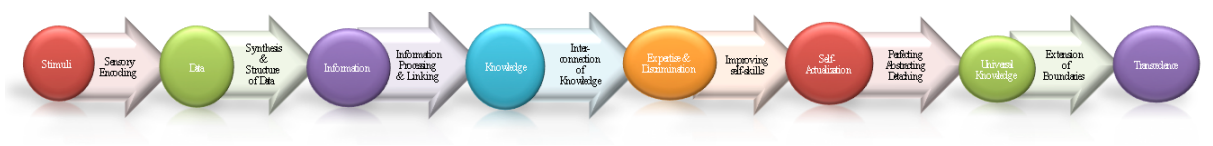

Fig. 2. Cognitive and Metacognitive processes required in order to move from a layer to another.

\section{$5 \quad$ Intelligence \& Knowledge}

Based on his two-factor theory of intelligence, using the general g-factor and the factor of specific intellectual abilities (s-factor), Spearman (1904) described the concept of General Intelligence. After using a technique known as factor analysis in order to examine a number of mental aptitude tests, Spearman concluded that scores on these tests were remarkably similar. People who performed well on one cognitive test, tended to perform well on other tests, while those who scored badly on one test tended to score badly on others. He concluded that intelligence is a general cognitive ability that could be measured and numerically expressed, as it depends on the accuracy with which the examination of intellectual fitness can be concluded, the hierarchical intellictive rank of the examination, as well as on the hierarchical intellective rank of the duties involved for any given post [44].

In an attempt to explain the different performance of individuals in the various tests, Thurstone proposed a multiple factor method, which was supplementary to the Spearman's two factor method, as there are no restrictions to the number of general 


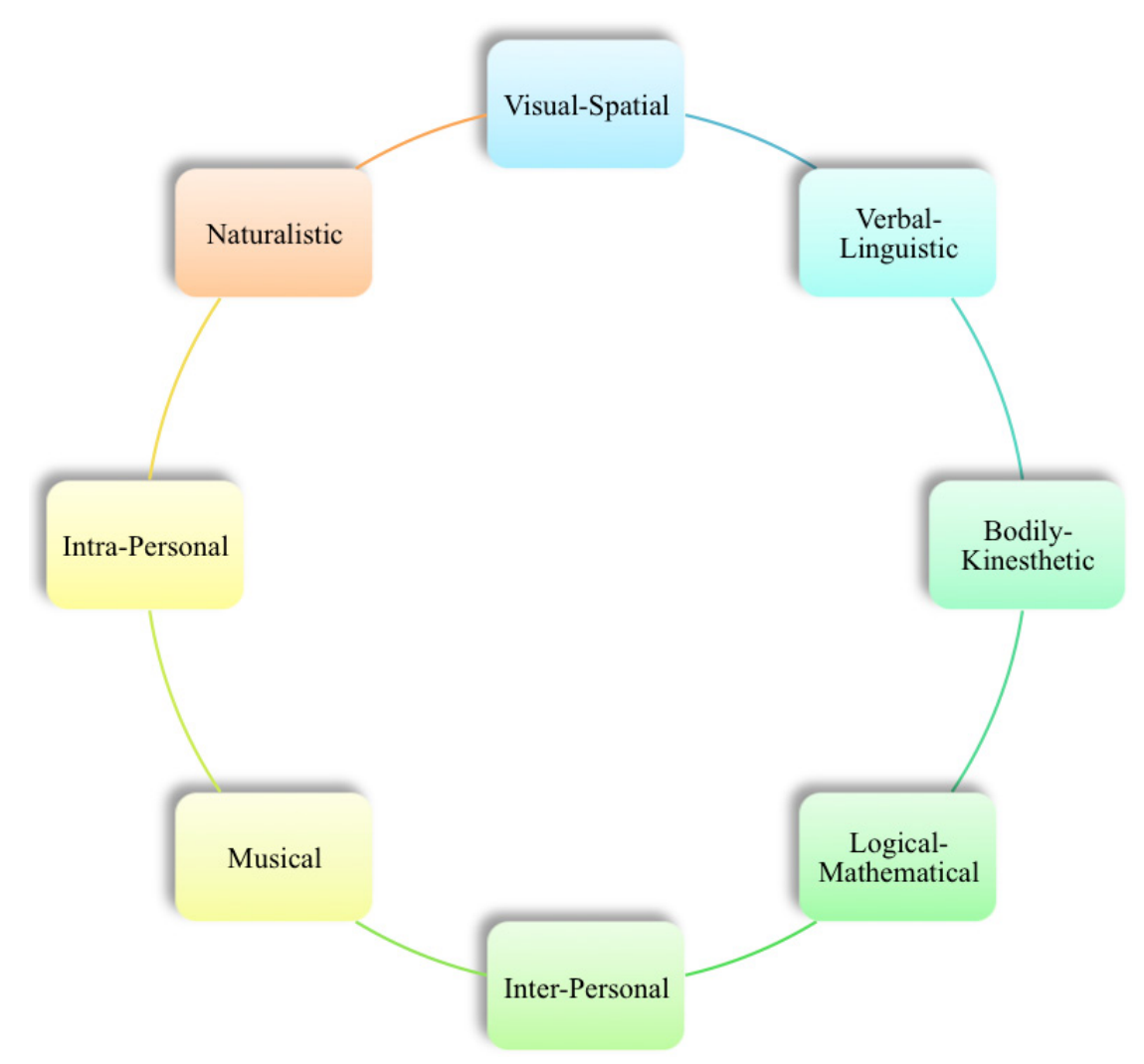

Fig. 3. The Eight Inteligences: Visual-Spatial Intelligence is related to the ability to perceive visual-spatial stimuli. Verbal-Linguistic Intelligence concerns paricular skills in different spoken and written functions of language. Bodily-Kinesthetic Intelligence refers to the ability to control body movements and skillful handling of objects. Logical-Mathematical Intelligence refers to arithmetic skills and mathematical thinking, as well as the ability to handle logical and numerical patterns. Inter-Personal Intelligence intelligence contains abilities to discern the purposes, the motivations and the moods of the others. Intra-Personal Intelligence is related to the ability of an individual to control his/her own feeling and self-knowledge. Musical Intelligence involves sensitivity to sounds, abilities to appreciate rhythm, execute and composite musical structures. Naturalistic Intelligence refers to the ability of an individual to detect and connect different elements in nature as well as the ability to recognize natural forms and patterns.

factors, as well as to the number of group factors [45]. In his book Primary Mental Abilities [46] he presented a different theory of intelligence. Instead of viewing intelligence as a single, general ability, his theory focused on seven different abilities: Verbal Comprehension (ability to understand verbal information and read), Reasoning (the ability to utilize data and draw conclusions), Perceptual Speed (quick and accurate perception ability), Numerical Ability (ability to perform quick and accurate arithmetic operations), Word Fluency (ability to handle oral and written language), 
Associative Memory (abilty to learn and recall relationships of unrelated data) and Spatial Visualization (ability to determine position and orientate).

Gardner's theory of multiple intelligences, as presented in his book Frames of Mind [47] and completed in his book Intelligence reframed: Multiple intelligences for the 21st century [48], changed the established until then viewpoints about intelligence, mentioning what researchers perceived as social skills, types of intelligence. Instead of focusing on the analysis of test scores, Gardner proposed that expressions of human intelligence are not a full and accurate depiction of people's abilities. His theory describes eight distinct intelligences (Visual-spatial, Verballinguistic, Bodily-Kineshetic, Logical-mathematical, Interpersonal, Musical, Intrapersonal, Naturalistic) that are based on skills and abilities that are valued with different cultures (Figure 3).

The Triarchic Theory of human Intelligence [49] argued that intelligence is related to the internal world of the individual, life experiences, as well as the external world of the individual. While he agreed with Gardner that intelligence is much broader than a single, general ability, he suggested that some of Gardner's intelligences should be considered as individual talents. According to Sternberg, in order to reach 'successful intelligence', individuals should have a balance between the three kinds of intelligence: Analytical Intelligence, which refers to problem solving abilities, Creative Intelligence, an aspect of intelligence that involves the ability to deal with situations using past experiences and current skills, and Practical Intelligence, refering to the ability to adapt to a changing environment.

Many researchers argue that inteligence can be enhanced by training, as working memory is highly correlated with intelligence. Furthermore, cognitive exercise and especially continuous training of working memory could slow down the process of intellectual decay [50]. Based on Gardner's theory of multiple intelligences, we propose that the 8-layer model of knowledge could be adapted to each one of the different types of intelligence, defining thus the levels of domain specific knowledge (Figure 4). The conquest of the top of this pyramid presupposes the 'Unity Level of Knowledge', the ultimate level which could be defined as total knowledge or omniscience [51, 52].

\section{Conclusion}

Based on the cognitive approach, the acquisition of knowledge is not the result of dependent learning, accumulation of information or teaching exclusively. It is a complex process in which the structure and the functions of the cognitive system play a key role. This article presents the different cognitive processes which are involved in the identification, selection, recruitment, processing, storage, organization and transformation of the subject. The development of meta-cognition plays a decisive role in the process of acquiring knowledge so that we have not only improvement of the academic performance of the individuals, but also better functioning of the whole cognitive mechanism. Through various intervention techniques and training of metacognition and cognitive skills, individuals could improve all different types of intelli- 


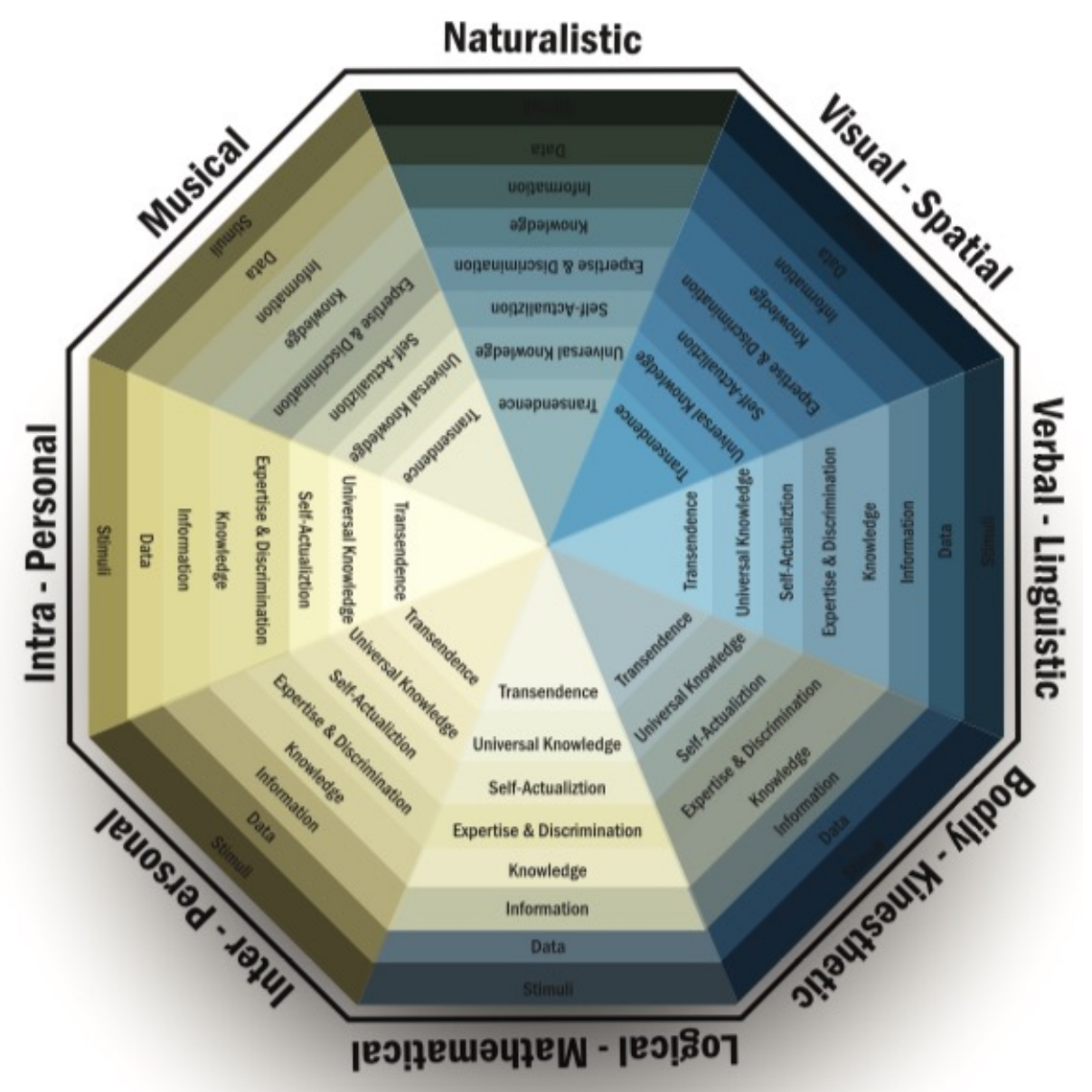

Fig. 4. The Consciousness-Intelligence-Knowledge Pyramid .

gence such as verbal, mathematical, and visual-spatial, as well as particular cognitive skills such as perception, understanding, memory in all its forms, pattern recognition and problem solving. With the pyramid of knowledge, we present all the eight levels that the individual has to conquer in order to reach transcendence. In essence, each higher level of the pyramid is a higher state of self-organization, awareness and consciousness, while at the same time reduced entropy levels. Indicative of the interdisciplinary application of the consciousness-intelligence-knowledge pyramid is the uniformity with the ISO's Open Systems Interconnection model (OSI model), a conceptual model for telecommunications and computer networks which integrates applied cognitive science [53]. 


\section{$7 \quad$ References}

[1] Piaget, J. (1936). Origins of intelligence in the child. London: Routledge \& Kegan Paul.

[2] Bloom, B. S. (1956). Taxonomy of educational objectives. Vol. 1: Cognitive domain. New York: McKay, 20-24.

[3] Anderson, L. W., \& Krathwohl, D. R. (Eds.). (2001). A taxonomy for learning, teaching and assessing: A revision of Bloom's Taxonomy of educational objectives: Complete edition, New York : Longman.

[4] Krathwohl, D. R. (2002). A revision of Bloom's taxonomy: An overview. Theory into practice, 41(4), 212-218. https://doi.org/10.1207/s15430421tip4104_2

[5] Biggs, J. B., \& Collis, K. F. (1982). Evaluation the quality of learning: the SOLO taxonomy (structure of the observed learning outcome). Academic Press.

[6] Gagné, R. M. (1970). The conditions of learning.

[7] Gagne, R. M., \& Briggs, L. J. (1974). Principles of instructional design. Holt, Rinehart \& Winston.

[8] Ackoff, R. L. (1989). From data to wisdom. Journal of applied systems analysis, 16(1), 39.

[9] Bellinger, G., Castro, D., \& Mills, A. (2004). Data, information, knowledge, and wisdom.

[10] Flavell, J. H. (1992). Cognitive development: Past, present, and future. Developmental psychology, 28(6), 998. https://doi.org/10.1037/0012-1649.28.6.998

[11] Patterson, R. E., Blaha, L. M., Grinstein, G. G., Liggett, K. K., Kaveney, D. E., Sheldon, K. C., ... \& Moore, J. A. (2014). A human cognition framework for information visualization. Computers \& Graphics, 42, 42-58. https://doi.org/10.1016/j.cag.2014.03.002

[12] Zins, C. (2007). Conceptual approaches for defining data, information, and knowledge. Journal of the Association for Information Science and Technology, 58(4), 479-493. https://doi.org/10.1002/asi.20508

[13] Hey, J. (2004). The data, information, knowledge, wisdom chain: the metaphorical link. Intergovernmental Oceanographic Commission, 26.

[14] Rowley, J. (2007). The wisdom hierarchy: representations of the DIKW hierarchy. Journal of information science, 33(2), 163-180. https://doi.org/10.1177/0165551506070706

[15] Zeleny, M. (2005). Knowledge-information autopoietic cycle: towards the wisdom systems. International Journal of Management and Decision Making, 7(1), 3-18. https://doi.org/10.1504/IJMDM.2006.008168

[16] Bender, S., \& Fish, A. (2000). The transfer of knowledge and the retention of expertise: the continuing need for global assignments. Journal of knowledge management, 4(2), 125137. https://doi.org/10.1108/13673270010372251

[17] Todd, R. J. (2006). From Information to Knowledge: Charting and Measuring Changes in Students' Knowledge of a Curriculum Topic. Information Research: An International Electronic Journal, 11(4), n4.

[18] Lazarus, R. S., \& Smith, C. A. (1988). Knowledge and appraisal in the cognitionemotion relationship. Cognition \& Emotion, 2(4), 281-300. https://doi.org/10.1080/0269 9938808412701

[19] Patel, V. L., Glaser, R., \& Arocha, J. F. (2000). Cognition and expertise: acquisition of medical competence. Clinical and Investigative Medicine, 23(4), 256-260.

[20] Lee, M. D., Steyvers, M., De Young, M., \& Miller, B. (2012). Inferring expertise in knowledge and prediction ranking tasks. Topics in cognitive science, 4(1), 151-163. https://doi.org/10.1111/j.1756-8765.2011.01175.x

[21] Fine, G. J. (1979). Knowledge and Logos in the Theaetetus. The Philosophical Review, 88(3), 366-397. https://doi.org/10.2307/2184956 
[22] Goldman, A. I. (1976). Discrimination and perceptual knowledge. The Journal of philosophy, 73(20), 771-791. https://doi.org/10.2307/2025679

[23] Rogers, C. R. (1959). A theory of therapy, personality, and interpersonal relationships: As developed in the client-centered framework (Vol. 3, pp. 184-256). New York: McGrawHill.

[24] Burleson, W. (2005). Developing creativity, motivation, and self-actualization with learning systems. International Journal of Human-Computer Studies, 63(4), 436-451. https://doi.org/10.1016/j.ijhcs.2005.04.007

[25] Maslow, A. (1965). Self-actualization and beyond.

[26] Pervin, L. A., \& John, O. P. (Eds.). (1999). Handbook of personality: Theory and research. Elsevier.

[27] Maslow, A. H. (1962). Some basic propositions of a growth and self-actualization psychology. Perceiving, behaving, becoming: A new focus for education, 34-49. https://doi.org/10.1037/14325-004

[28] Hawking, S. W. (1979). The path-integral approach to quantum gravity. In General relativity.

[29] Wilber, K. (2001). A theory of everything: An integral vision for business, politics, science and spirituality. Shambhala publications.

[30] Maslow, A. H. (1969). Various meanings of transcendence. The Journal of Transpersonal Psychology, 1(1), 56.

[31] Coward, D. D. (1996). Self-transcendence and correlates in a healthy population. Nursing research, 45(2), 116-121. https://doi.org/10.1097/00006199-199603000-00011

[32] Koltko-Rivera, M. E. (2006). Rediscovering the later version of Maslow's hierarchy of needs: Self-transcendence and opportunities for theory, research, and unification. Review of general psychology, 10(4), 302. https://doi.org/10.1037/1089-2680.10.4.302

[33] Levenson, M. R., Jennings, P. A., Aldwin, C. M., \& Shiraishi, R. W. (2005). Selftranscendence: Conceptualization and measurement. The International Journal of Aging and Human Development, 60(2), 127-143. https://doi.org/10.2190/XRXM-FYRA-7U0XGRC0

[34] Perkins, D. N., \& Salomon, G. (1989). Are cognitive skills context-bound? Educational researcher, 18(1), 16-25. https://doi.org/10.3102/0013189X018001016

[35] Steinberg, L. (2005). Cognitive and affective development in adolescence. Trends in cognitive sciences, 9(2), 69-74. https://doi.org/10.1016/j.tics.2004.12.005

[36] Hertzog, C., Kramer, A. F., Wilson, R. S., \& Lindenberger, U. (2008). Enrichment effects on adult cognitive development: Can the functional capacity of older adults be preserved and enhanced?. Psychological science in the public interest, 9(1), 1-65. https://doi.org/10.1111/j.1539-6053.2009.01034.x

[37] Bennet, A., \& Bennet, D. (2008). Moving from knowledge to wisdom, from ordinary consciousness to extraordinary consciousness. Vine, 38(1), 7-15. https://doi.org/10.1108/03055720810870842

[38] Flavell, J. H. (1979). Metacognition and cognitive monitoring: A new area of cognitivedevelopmental inquiry. American psychologist, 34(10), 906. https://doi.org/10.1037/0003066X.34.10.906

[39] Paris, S. G., \& Winograd, P. (1990). How metacognition can promote academic learning and instruction. Dimensions of thinking and cognitive instruction, 1, 15-51.

[40] Veenman, M. V., Van Hout-Wolters, B. H., \& Afflerbach, P. (2006). Metacognition and learning: Conceptual and methodological considerations. Metacognition and learning, 1(1), 3-14. https://doi.org/10.1007/s11409-006-6893-0 
[41] Shannon, C. E., \& Weaver, W. (1948). A mathematical theory of communication. Bell system technical journal, 27(379-423), 623-656. https://doi.org/10.1002/j.15387305.1948.tb00917.x

[42] Jaynes, E. T. (1957). Information theory and statistical mechanics. Physical review, 106(4), 620. https://doi.org/10.1103/PhysRev.106.620

[43] Von Glasersfeld, E. (1989). Cognition, construction of knowledge, and teaching. Synthese, 80(1), 121-140. https://doi.org/10.1007/BF00869951

[44] Spearman, C. (1904). " General Intelligence," Objectively Determined and Measured. The American Journal of Psychology, 15(2), 201-292. https://doi.org/10.2307/1412107

[45] Thurstone, L. L. (1931). Multiple factor analysis. Psychological Review, 38(5), 406-427. https://doi.org/10.1037/h0069792

[46] Thurstone, L. L. (1938). Primary mental abilities. Psychometric Monographs.

[47] Howard, G. (1983). Frames of mind: The theory of multiple intelligences. NY: Basics.

[48] Gardner, H. (1999). Intelligence reframed: Multiple intelligences for the 21st century. Basic books.

[49] Sternberg, R. J. (1997). The triarchic theory of intelligence. Guilford Press.

[50] Nisbett, R. E., Aronson, J., Blair, C., Dickens, W., Flynn, J., Halpern, D. F., \& Turkheimer, E. (2012). Intelligence: new findings and theoretical developments. American psychologist, 67(2), 130. https://doi.org/10.1037/a0026699

[51] Bohr, N. (1961). Atomic physics and human knowledge (p. 39). New York: Science Editions.

[52] Wilson, E. O. (1998). Consilience: The unity of knowledge. Issues in Science and Technology, 15(1), 90.

[53] Zimmermann, H. (1980). OSI reference model--The ISO model of architecture for open systems interconnection. IEEE Transactions on communications, 28(4), 425-432. https://doi.org/10.1109/TCOM.1980.1094702

\section{Authors}

Athanasios S. Drigas is a Director of Research at IIT - N.C.S.R. Demokritos. He is the Coordinator of Telecoms Lab and founder of Net Media Lab since 1996. From 1990 to 1999 he was the Operational manager of the Greek Academic network. He has been the Coordinator of Several International Projects, in the fields of ICTs, and e-services (e-learning, e-psychology, e-government, e-inclusion, e-culture etc). He has published more than 280 articles, 7 books, 25 educational CD-ROMs and several patents. He has been a member of several International committees for the design and coordination of Network and ICT activities and of international conferences and journals. (dr@iit.demokritos.gr).

Marios A. Pappas is a PhD Candidate in Cognitive Science. He holds a Bachelor degree in Mathematics and a Master degree in Special (Inclusive) Education. He is a research associate at N.C.S.R. Demokritos, Institute of Informatics and Telecommunications, Net Media Lab, Athens, Greece (mpap@iit.demokritos.gr ). 